\title{
Can Smart Waste Bins Solve the Dilemma of Household Solid Waste Sorting in China? A Case Study of Fuzhou City
}

\author{
Li-Ping Zhang', Zu-Ping Zhu ${ }^{1,2 *}$ \\ ${ }^{1}$ School of Economics and Management, Fuzhou University, Fuzhou Fujian, China \\ ${ }^{2}$ Fujian Soft Science Research Center, Fuzhou Fujian, China
}

Received: 25 October 2019

Accepted: 26 December 2019

\begin{abstract}
The increased amount of household solid waste (HSW) is one of the most serious environmental problems in China. The Chinese government has formulated some policies to promote HSW source sorting since 2000, but the problems of resident's intention have not been solved. At present, the Chinese government is launching a new nationwide campaign. In order to improve resident's willingness of HSW source sorting, some cities are installing smart waste bins in residential areas, since such bins can record inhabitants' HSW source sorting behavior conveniently. In this study, we try to understand how perceived external pressure and economic incentive moderate the relationships between perceived values and inhabitants' intention of HSW source sorting in the smart waste bin context. By using the hierarchical regression method to explore six different models which could show contributions of variables at different levels, we found that resident's perceived environmental value, perceived emotional value and perceived social value were positively related to their intention of HSW source sorting. We also found that perceived external pressure could significantly moderate the relationships between perceived emotional value/perceived social value and intention of HSW source sorting and that the three-way interactions of perceived external pressure, perceived environmental value/perceived emotional value/perceived sacrifice and economic incentive could also exert obvious influences according to our statistical analysis.
\end{abstract}

Keywords: household solid waste, smart waste bins, perceived external pressure, economic incentive, source sorting intention

\section{Introduction}

The growing amount of waste generated and the commensurate environmental pollution in developing

*e-mail: fzjg16@163.com countries have attracted increasing attention. Traditional ways of non-classified waste disposal are threatening the sustainable development of the economy and environment. China, with its economic development and process of urbanization, has come to produce the largest amount of household solid waste (HSW) in the world since 2004, and the amount of waste is increasing every year [1]. By 2030, the annual 
volume of household solid waste in China will reach 480 million tons, and global solid waste generation is expected to triple by 2100 [2]. Obviously, how to deal with the rapid growth of household solid waste is a huge challenge to the government. Landfill and incineration, which are currently the main means of household solid waste disposal in China, cannot keep up with the growth rate of waste production. In 2014, there were 604 national landfill sites in China [3], which together occupy a large amount of land and pollute both land and the surrounding groundwater networks. Many cities in China simply cannot find new places to landfill waste. Incineration is also not a preferable way since it can produce dioxins and other detrimental substances and sometimes it is also a way of wasting energy because auxiliary fuel is required to sustain the combustion [4]. The fundamental way out is to reduce the daily amount of household produced solid waste and recycle the still usable material in the waste [5]. The recyclable component of household solid waste reaches about 89.3\% [6]. HSW source sorting is recommended as one of the ideal ways to handle these kinds of problems [7].

Most developing countries have made an effort to sort HSW, but their goals are mostly not achieved. The recycling rates of Turkey and Iran, for instance, are still below $10 \%$ [8]. The Chinese government has formulated some policies to promote waste sorting since 2000 [9-10]. No satisfactory results, however, have been achieved due to the low level of public participation so far [11-12]. China's HSW management is still a hug challenge [13]. One of the main reasons is that the problem of residents' intention of HSW source sorting has not been solved. At present, the Chinese government is launching a new nationwide campaign to sort waste. Many cities are trying their best to improve the intention of residents to sort waste. Some cities, such as Fuzhou, a southern city in China, are promoting smart waste bins (Fig. 2) as a solution in their communities.

The operation process of smart waste bins is as follows: Residents sort HSW at home and take the sorted waste to smart waste bins nearby. After logging in to the system by face ID or using mobile phones to scan the QR code, residents put the sorted waste into the corresponding bins; the smart bins weigh the recyclable waste and put the converted credit points into the residents' accounts. If residents sort non-recyclable waste correctly, they can also receive some credit points. Residents can redeem the accumulated credit points for material rewards, such as daily necessities or banknotes. If a resident does not sort or sorts incorrectly, his/her ID will be identified through the ID mark on the waste bag. If one does not sort or sorts incorrectly more than three times, some volunteers in the neighborhood will come to his door to talk with him/her; if more than five times, his/her name may be listed on a blacklist on the apps for a certain amount of time as a way of warning. Other types of punishment can also be given.

Previous studies have identified factors influencing inhabitants' intention of HSW source sorting [14-16]. Knowledge of the environment has long been recognized as one of the most crucial factors influencing household solid waste disposal [17-18]. When individuals have more information about the benefits of waste sorting, they are more likely to practice it [19]. Even if some residents have enough information about waste sorting, they may be unwilling or unable to do it, because they thought HSW source sorting was troublesome, energydemanding and time-consuming. Storage of materials in house before disposal is also problematic because of space limitations and pest issues [20]. By experimenting in a community, Howenstine found that material rewards would stimulate residents' attitude on HSW source sorting - especially among lower-income groups [21] while others believed that economic incentives have no effects on waste sorting behaviors [22-23]. Salminado, Ari and Yilmaz believed that external pressure will influence inhabitants' intention of waste sorting [24-26]. Some researchers also recognized that demographic characteristics like age, gender, education, and income also play a certain role. For instance, Devall found that individuals who expressed environmental concern were generally young and well-educated and likely to reside in urban areas [27]. Income, for example, could directly influence behaviors of HSW source sorting. People who

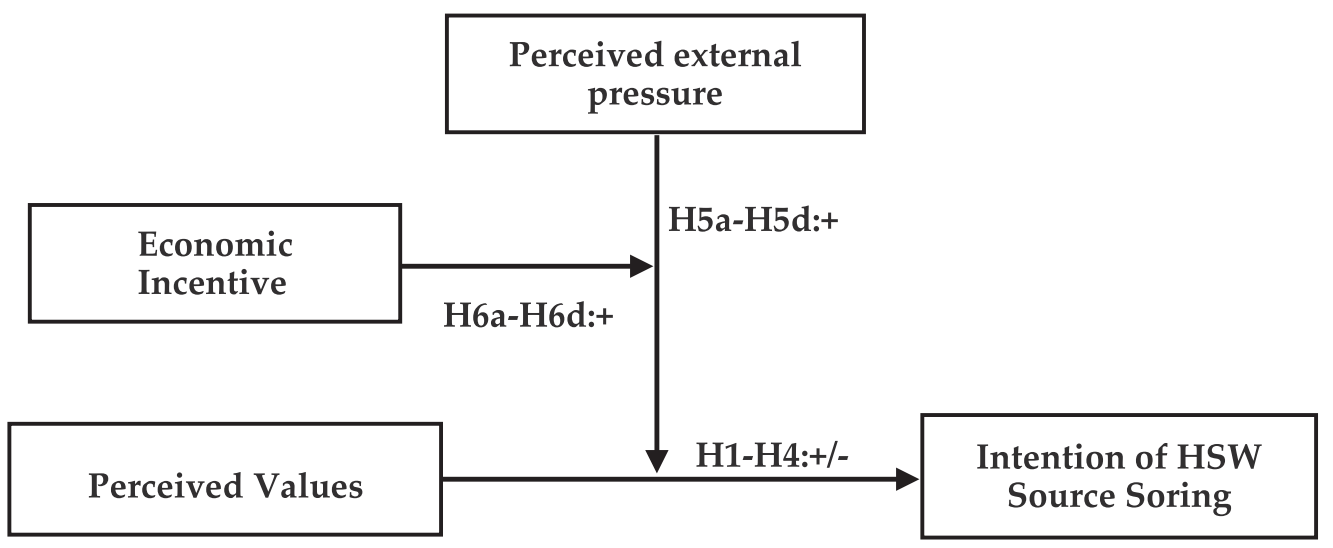

Fig. 1. Research model. 
make more money were more likely to participate in waste sorting and recycling than people who make less money [28].

The most widely used theory to explain human intention and behavior is the theory of planned behavior (TPB) [29], according to which the main determinants of behavior are intention of behavior, and the intention is related to one's attitude, subjective norm and perceived behavioral control. TPB is not impeccable, however. The TPB model is often criticized for its contradiction toward weak attitude-behavior correlation and for ignoring some important variables and hierarchical relationships among them $[1,30]$.

Based on previous studies and the current Chinese context, we incorporate two moderators into the basic value-intention framework and believe that perceived values have a direct influence on inhabitants' intention of HSW source sorting, and these influences would be moderated by resident's perceived external pressure and economic incentive hierarchically. Fig. 1 describes our research model.

\section{Material and Methods}

Perceived values can be defined as overall assessment of utility of a product or an activity based on perceptions of what is received and what is given [31]. An individual will evaluate what is right for the perceived cost of the offering, including monetary costs and nonmonetary consumption, such as time costs, energy costs, and then he will determine whether to practice an activity [32]. It is evident that an individual's perceived values positively relate to his behavioral intentions.

Maloney and Ward believe that people's understanding of environmental knowledge and their feelings of the benefits of a specific behavior will have a profound impact on people's pro-natural behavior [33-34]. Individuals' knowledge of the environment can make them realize how their pro-environmental behavior can benefit the environment. Therefore, we believe that perceived environmental value may positively influence people's intention of doing a specific activity. Then, we have our first hypothesis:

Hypothesis 1: Perceived environmental value is positively related to HSW source sorting intention.

Emotional value refers to the utility derived from feelings of affective states generated by the process of an activity [35]. When an individual decides whether to engage in a specific activity, feelings of satisfaction, trust, belonging and pleasure he has experienced before or he predicts to experience will play a role in his decision-making. Individuals use emotions to identify their unconscious needs and take according actions that will satisfy them [36]. Positive emotions such as happiness, pride, hope, affection, etc. can make people have greater intention of practicing a specific behavior [37]. Hence, we propose the following hypothesis:

Hypothesis 2: Perceived emotional value is positively related to HSW source sorting intention.

Reputation refers to other people's impression and cognition of the subject. Mayhew and other scholars believe that reputation of an individual is closely related to his historical behaviors [38]. If a person wants to keep a good reputation, he has to satisfy other people's moral expectations of him. In China, Mianzi also plays a vital role [39]. If an activity has a social value of Mianzi, it will tend to promote the intention of that activity. Otherwise, it may block the emergence and development of immoral behavior. Thus, we hypothesize the following:

Hypothesis 3: Perceived social value is positively related to HSW source sorting intention.

Perceived sacrifice refers to individuals' perceived giving-up when he performs a certain behavior. When
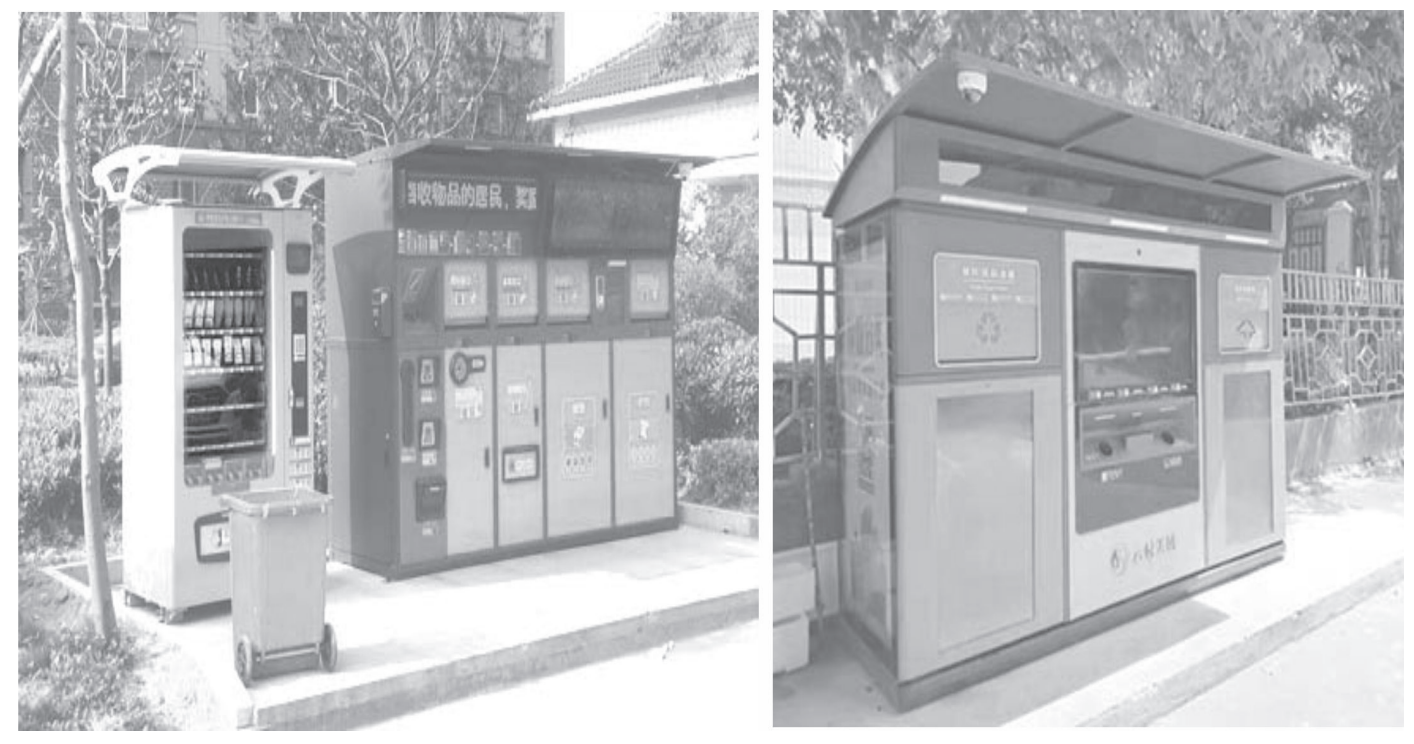

Fig. 2. Smart waste bins in residential areas. 
a behavior needs individuals to sacrifice and reduces the comfort of their lives, their intention of that behavior is supposed to be influenced. HSW source sorting will surely cost individuals more than the traditional method of waste disposal. These sacrifices include monetary sacrifice and nonmonetary sacrifice [40]. Monetary sacrifice refers to the money individuals have to pay for extra waste bags and other disposal facilities. Non-monetary sacrifice usually includes time, energy and space at home when practicing HSW source sorting. We then hypothesize:

Hypothesis 4: Perceived sacrifice is negatively related to HSW source sorting intention.

Perceived eternal pressure refers to pressure from government or community policies. government and community show their willingness to change the current situation of HSW source sorting by formulating and publicizing policies.

Smart waste bins can monitor inhabitants' waste disposal behavior in real time through a supervising program. If there are any violations, the program can record them into inhabitants' waste disposal accounts. Community volunteers can give inhabitants education, persuasion or warning according to the records of inhabitants' disposal accounts. If there are serious violations, some corresponding punishment measures can be given.

This pressure can supposedly moderate the relationship of perceived values and intention of HSW source sorting. We then have the following hypothesis:

Hypothesis 5a: perceived eternal pressure moderates the relationship between perceived environmental value and HSW source sorting intention.

Hypothesis 5b: perceived eternal pressure moderates the relationship between perceived emotional value and HSW source sorting intention.

Hypothesis 5c: perceived eternal pressure moderates the relationship between perceived social value and HSW source sorting intention.

Hypothesis 5d: perceived eternal pressure moderates the relationship between perceived sacrifice and HSW source sorting intention.

Traditionally, recyclable material separating behaviors are mostly carried out by some elderly inhabitants who separate recyclable material casually and take it to itinerant waste buyers in order to receive some money [41]. Since this kind of waste-sorting behavior is inconvenient and time-consuming, most inhabitants will not practice HSW source sorting_when disposing. But with smart waste bins, residents can obtain economic rewards more conveniently.

Smart waste bins can weigh delivered recyclable waste directly, and give residents corresponding credit points according to the weight and unit price. The credit points can be converted into daily necessities or banknotes. In addition, for non-recyclable waste, if it is classified correctly, corresponding credit points will also be awarded to residents. As Thøgersen supposed, incentives can act as positive feedback about individual performance and may enhance recipients' feeling of self-efficacy and, in turn, increase their intention to contribute [42]. We then hypothesize:

Hypothesis 6a: The moderating effect of perceived eternal pressure on the relationship between perceived environmental value and HSW source sorting intention is stronger when economic incentive is higher.

Hypothesis 6b: The moderating effect of perceived eternal pressure on the relationship between perceived emotional value and HSW source sorting intention is stronger when economic incentive is higher.

Hypothesis 6c: The moderating effect of perceived eternal pressure on the relationship between perceived social value and HSW source sorting intention is stronger when economic incentive is higher.

Hypothesis 6d: The moderating effect of perceived eternal pressure on the relationship between perceived sacrifice and HSW source sorting intention is stronger when economic incentive is higher.

In addition to the underlying constructs described above, this study includes gender, age, income, educational level and occupation as control variables. Based on a summary of previous studies [27, 28, 43, 44], we suppose that these socio-demographic variables may contribute, to some extent, to their intention of HSW source sorting.

\section{Material of Hypothesis Testing}

All the data in this paper come from an onsite questionnaire survey conducted in Fuzhou city in 2019. Fuzhou, the capital of Fujian Province, is located in southeastern China. It has a terrestrial area of $1043 \mathrm{~km}^{2}$ and the population totals more than 7 million. Fuzhou is one of the most urbanized and dynamic cities in China [45]. Since the 1980s, Fuzhou has undergone a rapid process of urbanization with an urbanization rate is $70.3 \%$ in 2019 . The total waste generation of Fuzhou urban districts has increased steadily in the last 20 years, and in 2019 the amount is more than 4000 tons per day.

The survey was conducted by door-to-door interview in the targeted communities. A total of 511 responses were finally collected. By excluding the responses, which took less than 50 seconds to answer and responses with the same score of most of options, 495 responses were finally believed to be valid. The survey sample shows 311 female respondents (accounting for 62.8\%) and 184 male respondents (accounting for $37.2 \%$ ). There are 449 respondents with a college degree or below. Among 495 respondents, 246 (49.7\%) had incomes below 4000 and $249(50.3 \%)$ above 4000 . Most respondents are below the age of $45(84 \%)$.

To measure each latent variable in our valueintention model, we developed our constructs and measures, which were mainly adapted from previous validated studies. Responses were captured on Likert-type scales ranging from 1 (strongly disagree) to 5 (strongly agree) for each statement. 


\section{Methods of Hypothesis Testing}

In order to test the hypotheses given above, a moderated regression analysis was conducted. Because three interaction terms were included in the equation, we standardized all variables to reduce the potential effects of multicollinearity [46]. Following the instructions of Takeuchi [47], we carried out six steps for multiple regression analysis - the results of which can be seen in Table 3 .

In the first step, we put the six control variables (gender, age, income, education level and occupation) into model 1, and the results are shown in the row of Table 3 under the name of Model 1. In order to test the main effects, in the second step we added perceived external pressure and the four dimensions of perceived values (perceived environmental value, perceived emotional value, perceived social value and perceived sacrifice). The results of the second step are listed in the row of Table 3 under the name of Model 2. Thirdly, the two-way interaction terms between perceived external pressure and perceived values were added in, and results are listed in model 3 of Table 3. In the fourth step, we included economic incentive to control its main effect because economic incentive is an additional moderator of the relationships among perceived external pressure, perceived values, and intention of HSW source sorting. The results of this step can be seen in model 4 of Table 3. In the fifth step, the two-way interaction terms between economic incentive and perceived external pressure, and between economic incentive and perceived value were added in. The results are listed in the row of Table 3 under the name of model 5. Lastly, the three-way interaction terms among perceived external pressure, perceived values and economic incentive were added in and the results can be seen in the row of Table 3 under the name of model 6.

Together with the regression results, we examined the variance inflation factors (VIF) to estimate the possibility that multicollinearity affects the results. As can be seen in Table 3, in each of the six steps in the hierarchical regression model, the mean VIFs were lower than 2.0, indicating that multicollinearity does not affect the weights of the controls or hypothesized variables [48].

\section{Results and Discussion}

\section{Measurement Model Results}

The purpose of measurement model tests is to check the reliability and validity of constructs. We have to make sure all the constructs meet the statistical standards. First, we conducted a confirmatory factor analysis (CFA) in our study by using AMOS 21.0, which can confirm the measurement model fit. Seven indexes of model-fit measurements were employed to estimate the measurement model fit: The chi-square/degrees of freedom $(\mathrm{x} 2 / \mathrm{d}$.f. $)=1.500$; the goodness-of-fit index $(\mathrm{GFI})=0.943$; root mean square error of approximation $($ RMSEA $)=0.032$; normed fit index $(\mathrm{NFI})=0.940$; incremental fit index (IFI) $=0.979$; Tucker-Lewis index(TLI) $=0.975$ and the comparative fit index $(\mathrm{CFI})=0.979$. All the model-fit indexes are more than their acceptance levels suggested in the prior literature [49]. Therefore, we can believe that the measurement model has good fit with the data collected.

In addition to the model fit, reliability, convergent validity, and the discriminant validity of the scale were examined. In order to test the reliability of our measurement model we used the index of composite reliability (CR) since it is a more preferred index than the index of Cronbach's alpha [50]. The formula of CR specifies that:

$$
\mathrm{CR} \eta=\frac{\left(\Sigma \lambda \gamma_{i}\right)^{2}}{\left(\sum \lambda \gamma_{i}\right)^{2}+\left(\sum \varepsilon_{i}\right)}
$$

...where $\mathrm{CR} \eta=$ composite reliability for $\eta$; $\lambda_{\gamma i}=$ standardized loading for scale item $\gamma_{i}$, and $\varepsilon_{i}=$ measurement error for scale item. Table 1 lists all values of $\mathrm{CR}$ for each latent variable. The $\mathrm{CRs}$ of the measurement items are all above 0.80 , which means they are all acceptable since CR in an adequate model

Table 1. Measurement model.

\begin{tabular}{|c|c|c|c|c|c|}
\hline Construct & Mean & S.D. & AVE & CR & Cronbach's alpha \\
\hline Perceived external pressure (PRS) & 3.596 & .872 & .555 & .833 & .832 \\
\hline Economic incentive (INC) & 3.329 & .936 & .551 & .831 & .830 \\
\hline Perceived Environmental & 3.88 & .923 & .584 & .808 & .807 \\
\hline \multicolumn{7}{|c|}{ Value (EVN) } \\
\hline Perceived Emotional Value (EMT) & 3.487 & .919 & .623 & .832 & .830 \\
\hline Perceived Social Value (SOC) & 3.437 & 1.040 & .629 & .835 & .831 \\
\hline Perceived Sacrifice (SCF) & 2.402 & .992 & .569 & .840 & .838 \\
\hline Intention of Waste Sorting (INT) & 3.932 & .884 & .589 & .851 & .851 \\
\hline
\end{tabular}


should be greater than 0.6 or 0.7 for exploratory and confirmatory purpose respectively [51].

Then index of average variance extracted (AVE) was used to examine the convergent validity of our scales. Average variance extracted was calculated as:

$$
v_{\eta}=\frac{\sum \lambda \gamma_{i}^{2}}{\sum \lambda \gamma_{i}^{2}+\sum \varepsilon_{i}}
$$

...where $v_{\eta}=$ average variance extracted for $\eta$; $\lambda_{\gamma i}=$ standardized loading for scale item $\gamma_{i}$, and $\varepsilon_{i}=$ measurement error for scale item $\gamma_{i}$. All values listed in Table 1 are greater than 0.5 , which confirms an acceptable convergent validity for the scales in our model [52]. In Table 2, the data on the diagonal are the square roots of the AVE values; the other data in the table are the correlation coeffcients. The results suggest that our instrument has good discriminant validity.

By all the results given above, we can safely draw the conclusion that measurement of all constructs in our research model exhibits high reliability and good validity.

\section{Results of Hypothesis Testing}

Hypotheses 1-3 suggested that perceived values are positively related to inhabitants' intention of HSW source sorting. Hypotheses 4 suggested that perceived sacrifice is negatively related to inhabitants' intention of HSW source sorting. When we added the four independent variables in the second step - perceived environmental value (ENV), perceived emotional value (EMT), perceived social value (SOC), perceived sacrifice (SCF) - we can clearly see in the result of Model 2 that the first three variables of perceived environmental value $(b=0.16, p<0.001)$, perceived emotional value $(b=0.06, p<0.001)$, and perceived social value $(b=0.18, p<0.001)$ positively influence inhabitants' intention of HSW source sorting while the last variable perceived that sacrifice $(b=-0.41, p<0.001)$ has a negative effect on inhabitants' intention of HSW source sorting. Since the four variables are statistically significant, hypotheses 1-4 were supported by our study.

Hypotheses $5 \mathrm{a}$ to $5 \mathrm{~d}$ suggested that the relationship between perceived values and intention of HSW source sorting would be moderated by perceived external pressure. If perceived external pressure is big enough, individuals may not be necessary to have high level of perceived values in order to have a high level of intention of HSW source sorting. The results of Model 3 which are listed in Table 3 can show us that perceived external pressure can moderate the relationship between perceived emotional value and the intention of HSW source sorting $(b=-.09, p<0.01)$, and the relationship between perceived social value and intention of HSW source sorting $(\mathrm{b}=.007, \mathrm{p}<0.05)$, but the moderating effects on the relationship between perceived environmental value $(b=-.02, p>0.05)$ and perceived sacrifice $(b=-.04, p>0.05)$ and intention of HSW source sorting are not statistically significant.

Hypotheses $6 \mathrm{a}$ to $6 \mathrm{~d}$ proposed that moderating effects on the relationship between perceived values and the intention of HSW source sorting would be moderated by economic incentive. That is to say, the relationship between perceived environmental value/perceived emotional value/perceived social value/perceived sacrifice and intention of HSW source sorting would be weakened if the level of perceived external pressure is higher, more strongly so when the level of economic incentive is higher. To test these hypotheses, in step 6 we included the three-way interaction among perceived values, perceived external pressure and economic incentive into Model 6. The results of Model 6, which can also be seen in Table 3, show that the interaction was statistically significant for perceived environmental value $(b=0.05, p<0.01)$, perceived emotional value $(b=0.05, p<0.01)$ and perceived sacrifice $(b=0.11$, $\mathrm{p}<0.001)$, but not for perceived social value $(\mathrm{b}=-0.002$, $\mathrm{p}>0.05$ ).

To further explore these moderating effects, we used the PROCESS tool designed by Hayes [53] to plot these

Table 2. Correlations and discriminant validity.

\begin{tabular}{|c|c|c|c|c|c|c|c|}
\hline & ACC & INC & ENV & EMT & SOC & SCF & INT \\
\hline PRS & .745 & & & & & & \\
\hline INC & .439 & .742 & & & & & \\
\hline ENV & .287 & .374 & .764 & & & & \\
\hline EMT & .097 & .120 & .178 & .789 & & & \\
\hline SOC & .179 & .372 & .362 & .247 & .793 & & \\
\hline SCF & -.402 & -.547 & -.458 & -.204 & -.387 & .754 & \\
\hline INT & .527 & .739 & .541 & .263 & .491 & -.712 & .767 \\
\hline
\end{tabular}

Note: PRS = Perceived external pressure; INC = Economic incentive; ENV = Perceived Environmental Value; EMT = Perceived Emotional Value; $\mathrm{SOC}=$ Perceived Social Value; $\mathrm{SCF}=$ Perceived Sacrifice; INT = Intention of HSW source sorting;

Diagonal elements represent the square root of AVE for that construct. 
Table 3. Results of moderated regression analysis.

\begin{tabular}{|c|c|c|c|c|c|c|c|}
\hline \multirow[b]{2}{*}{ Step } & \multirow[b]{2}{*}{ Variable } & \multicolumn{6}{|c|}{ Intention of HSW source sorting } \\
\hline & & Model 1 & Model 2 & Model 3 & Model 4 & Model 5 & Model 6 \\
\hline \multirow{6}{*}{1} & Intercept & 4.30 & 4.21 & .01 & .012 & .040 & .052 \\
\hline & Gender & -0.03 & .01 & .004 & .01 & .01 & .01 \\
\hline & Age & -.004 & .01 & .02 & -.02 & -.02 & -.01 \\
\hline & Income & $.12 *$ & $.07 *$ & $.07 *$ & .04 & -.04 & .04 \\
\hline & Education level & $.34 * * *$ & $.11^{* * *}$ & $.10^{* * *}$ & $.09 * * *$ & $.08 * *$ & $.07 * *$ \\
\hline & Occupation & -.01 & $-.14 * * *$ & $-.13 * * *$ & $-.08 * *$ & $-.09 * *$ & $-.10 * * *$ \\
\hline \multirow{5}{*}{2} & PRS & & $.29 * * *$ & $.28 * * *$ & $.18^{* * *}$ & $.20 * * *$ & $.23 * * *$ \\
\hline & ENV & & $.16^{* * *}$ & $.16^{* * *}$ & $.13 * * *$ & $.14^{* * *}$ & $.12 * * *$ \\
\hline & EMT & & $.06^{* * *}$ & $.09 * * *$ & $.10^{* * *}$ & $.07 * * *$ & $.05 * * *$ \\
\hline & SOC & & $.18^{* * *}$ & $.20 * * *$ & $.14 * * *$ & $.16^{* * *}$ & $.15^{* * *}$ \\
\hline & SCF & & $-.41 * * *$ & $-.39 * * *$ & $-.27 * * *$ & $-.28 * * *$ & $-.32 * * *$ \\
\hline \multirow{4}{*}{3} & PRS x ENV & & & -.10 & -.02 & -.02 & -.02 \\
\hline & PRS x EMO & & & $-.08 * *$ & $-.07 * *$ & $-.09 * *$ & $-.09 * *$ \\
\hline & PRS x SOC & & & $-.002 * *$ & $-.06 * *$ & $.007 *$ & $.001 *$ \\
\hline & PRS x SCF & & & -.05 & -.03 & -.04 & -.02 \\
\hline 4 & INC & & & & $.36^{* * *}$ & $.33 * * *$ & $.35 * * *$ \\
\hline \multirow{5}{*}{5} & PRS $x$ INC & & & & & $-.06^{*}$ & -.04 \\
\hline & INC $x$ ENV & & & & & .02 & .03 \\
\hline & INC x EMO & & & & & $.06 * *$ & .05 \\
\hline & INC $\mathrm{x}$ SOC & & & & & $-.11 * * *$ & $-.11 * * *$ \\
\hline & $\mathrm{INC} \times \mathrm{SCF}$ & & & & & -.01 & .006 \\
\hline \multirow{9}{*}{6} & PRS $x$ ENV $x$ INC & & & & & & $.05 * *$ \\
\hline & PRS $x$ EMO $x$ INC & & & & & & $.05 * *$ \\
\hline & PRS $x$ SOC $x$ INC & & & & & & -.002 \\
\hline & PRS x SCF x INC & & & & & & $.11 * * *$ \\
\hline & $\mathrm{R}^{2}$ & .16 & .69 & .70 & .78 & .79 & .80 \\
\hline & $\mathrm{F}$ & 18.18 & 106.71 & 80.72 & 109.92 & 86.90 & 78.39 \\
\hline & $\Delta \mathrm{R}^{2}$ & & 0.53 & 0.01 & 0.07 & 0.01 & 0.01 \\
\hline & $\Delta \mathrm{F}$ & & 164.79 & 5.61 & 155.32 & 4.78 & 8.46 \\
\hline & Mean VIF & 1.17 & 1.34 & 1.38 & 1.44 & 1.68 & 1.87 \\
\hline
\end{tabular}

Note: $\mathrm{N}=495 ; \mathrm{PRS}=$ Perceived external pressure; $\mathrm{INC}=$ Economic incentive; $\mathrm{ENV}=$ Perceived Environmental Value; EMT $=$ Perceived Emotional Value; SOC = Perceived Social Value; SCF = Perceived Sacrifice; INT = Intention of HSW source sorting;

$* \mathrm{p}<0.05 .{ }^{* *} \mathrm{p}<0.01 .{ }^{* * *} \mathrm{P}<0.001$.

interaction effects. This tool enables a more modern and up-to-date procedure for moderation analysis [53]. By using this method, we first interpreted the significance level of the relationships between the four perceived values and intention of HSW source sorting under different levels of perceived external pressure respectively. Figs 2(a-d) in Table 4 show the results of these tests.

As shown in Fig. 2a), the slope is steeper when the value of perceived external pressure is at a low level and the slope becomes flat when the value of perceived external pressure is at a high level. This 
Table 4. Moderating effects of PRS and INC.

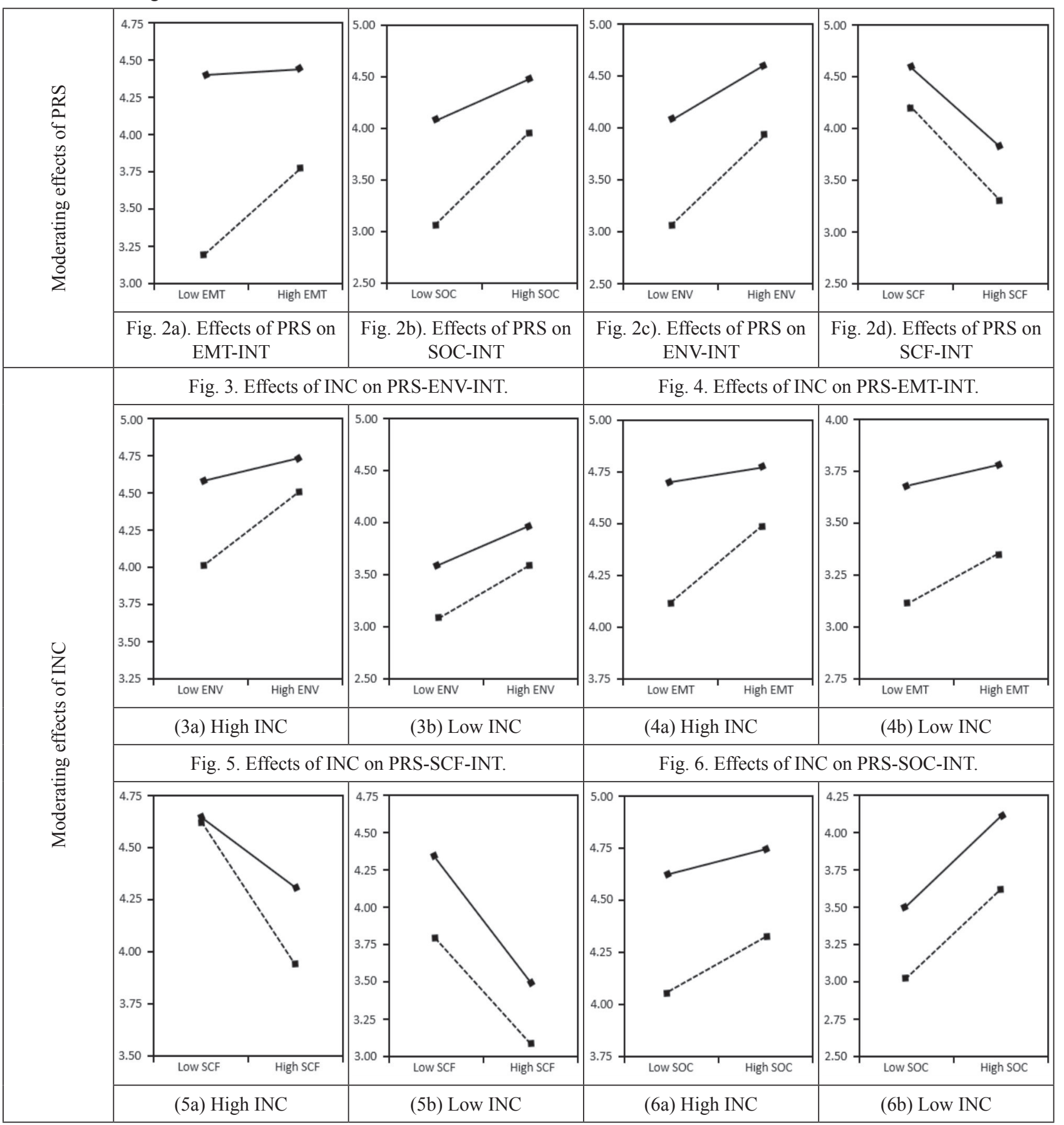

Note: PRS = Perceived external pressure; INC = Economic incentive; ENV = Perceived Environmental Value; EMT = Perceived Emotional Value; $\mathrm{SOC}=$ Perceived Social Value; SCF = Perceived Sacrifice; INT = Intention of HSW source sorting; $\neg$ - = High PRS; -

means that at high levels of perceived external pressure, the moderating effect on the relationship between perceived emotional value and the intention of HSW source sorting tends to be higher than at a low level of perceived external pressure. This result suggests that the level of perceived external pressure can moderate the relationship between perceived emotional value and the intention of HSW source sorting, thus lending support to hypothesis $5 \mathrm{~b}$.
Similarly, in Fig. 2b), at a low level of perceived external pressure, the moderating effect on the relationship between perceived social value and the intention of HSW source sorting tends to be lower than at high perceived external pressure. This result suggests that a high level of perceived external pressure can moderate the relationship between perceived social value and the intention of HSW source sorting, thus hypothesis $5 \mathrm{c}$ was supported by this analysis. 
In Figs. 2c) and 2d), however, we can see that there is no big difference among the three slopes regardless of the level of perceived external pressure. This means that the moderating effect of perceived eternal pressure on the relationship between environmental value and the intention of HSW source sorting and on the relationship between perceived sacrifice and the intention of HSW source sorting are not significant. These results confirm that perceived external pressure had no significant moderating effect on these two variables.

Hypotheses $6 \mathrm{a}$ to $6 \mathrm{~d}$ predict that perceived external pressure can moderate the relationship between perceived values and the intention of HSW source sorting and the moderating effects can be stronger when the level of economic incentive is high. To further study these moderating effects, we also used the PROCESS tool to plot these interaction effects. Fig. 3 in Table 4 shows the three-way interaction effect among economic incentive, perceived environmental value, and perceived external pressure on intention of HSW source sorting. As shown in Fig. 3a), when the economic incentive is high, the strengthening effect of perceived external pressure on the relationship between perceived environmental value and intention of HSW source sorting is more significant since the slopes of the line is comparatively flatter when economic incentive is high. In Fig. 3b), perceived environmental value is positively related to the intention of HSW source sorting whether perceived external pressure is high or low. The H6a is thus supported by these results.

Similarly, Fig. 4 in Table 4 shows the three-way interaction effect of economic incentive, perceived emotional value, perceived external pressure on intention of HSW source sorting. As shown in Fig. 4, when the level of economic incentive is at a high level, the moderating effect of perceived external pressure is more significant than when economic incentive is at a low level. Hence hypothesis $6 \mathrm{~b}$ is supported.

Fig. 5 in Table 4 describes the three-way interaction effect among economic incentive, perceived sacrifice and perceived external pressure on HSW source sorting intention. As depicted in Fig. 5, when economic incentive is at a high level, the slope of the high level of perceived external pressure is comparatively flatter than when perceived external pressure is at a low level, but not in situations of low economic incentive. Thus hypothesis $6 \mathrm{~d}$ is supported by these results.

Fig. 6 in Table 4 displays how the moderating effect of economic pressure on the relationship between perceived social value and HSW source sorting intention was maintained, regardless of the level of economic incentive. These results indicate that the three-way interaction of economic incentive, perceived social value and perceived external pressure on intention of HSW source sorting is not statistically significant. Hence, these empirical results provide support for moderating the effect of economic incentive on perceived environmental value, perceived emotional value and perceived sacrifice, but not on perceived social value.

To summarize, hypotheses 1-4, hypothesis 5b, hypothesis 5c, hypothesis $6 \mathrm{a}$, hypothesis $6 \mathrm{~b}$ and hypothesis $6 \mathrm{~d}$ were all supported, while hypothesis 5a, hypotheses $5 \mathrm{~d}$ and hypothesis $6 \mathrm{c}$ were not supported by previous statistical results.

\section{Findings and Discussion}

Five main findings can be drawn from our studies. First of all, the fact that the variables of education level and EVN are significant in all six models indicates that education exerts an important influence on residents' willingness of HSW source sorting. This is understandable, since education can enhance residents' environmental awareness. This finding is consistent with the findings of Digiacomo [54] and Singer [55]. Digiacomo believed that environmental awareness of people was the key to promoting waste separation at source [54]. Singer, who studied cases of cities in Vietnam and Indonesia, believed that government should be able to solicit continuous funding for systematic waste education and awareness campaigns to improve waste management [55]. A case study from Brixworth in the UK also found that residents who understand that waste sorting behavior is morally correct will have a high positive attitude toward HSW source sorting programs [56]. Education is essential to improving residents' HSW source-sorting skills [57], which is also is necessary for successful implementation of waste-sorting programs.

Secondly, the result that the variable of SCF is significant in all models indicates that convenience can influence residents' willingness to sort waste. If the residents have to sacrifice too much time, energy, and space, they are less likely to participate in the program. This indication is consistent with previous studies that indicated that waste-sorting behavior could be facilitated by convenience [58, 59]. Smart waste bins should be installed near residential areas, and the number of these facilities should be sufficient. At the same time, their operation should not be too complicated.

Thirdly, cultivating a supportive atmosphere is necessary. Consensus can be obtained that residents who do not practice HSW source sorting will not only damage the environment, but also damage their own social image. In order to keep an image of themselves as socially responsible people, duty-oriented individuals would perform waste sorting and recycling [60]. Emotional value also matters. If inhabitants feel pride and delight when performing HSW source sorting and feel guilty when not performing it, they would form a positive attitude towards HSW source sorting.

Fourthly, the testing results of hypothesis $5 \mathrm{~b}$ and hypothesis 5c imply that external pressure is conditionally necessary. This can interact with perceived emotional/social value in order to affect inhabitants' willingness for HSW source sorting. External pressure 
can strengthen people's motivation - especially for those who are not motived enough. People usually have the instinct to escape potential social criticism or sanctions by others [61]. To make specific policies and to strictly implement these policies are the key measures to form external pressure on residents. This was supported by some previous studies [57, 62, 63]. Efficient eternal pressure is necessary, and if residents believe the effectiveness of local government's wastedisposal legal instruments, individuals are more likely to perform HSW source sorting. HSW source sorting standards can be internalized or introjected as personal norms through repeated compliance and cooperation in the longer term [62]. Pressure from neighbors can also play a critical role. Social modeling, which means community members who have performed waste sorting well, could act as block leaders to encourage actions of nonparticipants via communication, demonstration and/ or door-stepping campaigns [63].

Finally, since hypothesis $6 \mathrm{a}, 6 \mathrm{~b}$ and $6 \mathrm{~d}$ were all supported, we can conclude that economic incentive can interact with external pressure along with most perceived values to stimulate residents' intention. The role of economic incentive is still inconclusive as per previous studies. Some scholars have supposed that economic incentive is crucial [21], while others have denied its importance [22, 23, 64]. We believe that giving people material rewards can make them feel positive about their performance and improve their sense of gain. Just as $\mathrm{Xu}$ implied, rewarding participation in the provision of public goods would effectively induce individual contributions [65]. Economic reward can reinforce positive attitudes, give external stimulus to those who view the program negatively and encourage positive behavior.

\section{Conclusions}

This research contributes new insights to HSW source sorting by investigating the hierarchical moderating roles of external pressure and economic incentive in the smart waste bin context. It is unanimously acknowledged that waste disposal is one of the greatest threats to the natural environment [66], and waste needs to be sorted at the source. HSW source sorting is an ideal and effective solution to many waste-related problems [7, 57]. Some waste can be recycled and used for energy or new products [67]. HWS source sorting can also reduce heavy metal pollution and incineration-related air pollution [68]. At present, developing countries have more or less encountered the problem of residents' intention of HSW source sorting. Based on previous experience, China is currently launching a new campaign of HSW source sorting. Some Chinese cities such as Fuzhou have put forward some new measures, such as the installation of smart waste bins in residential areas. Compared with traditional waste bins, smart waste bins are a more convenient way to form external pressure since they can record every non-conforming behavior and are also an efficient way to give residents economic rewards according to their credit points, which are accumulated through the amount of recyclable material and the times of right HSW source-sorting behavior.

In this study, we studied how perceived external pressure and economic incentive can moderate relationships between perceived values and inhabitants' intention of HSW source sorting. We found that perceived external pressure has a significant moderating effect on the relationship between perceived emotional value/perceived social value and the intention of MSW source sorting, but this is not the case for perceived environmental value and perceived sacrifice. By statistical analyses, we also believed that economic incentive plays a significant regulating role. To be specific, the relationship among perceived external pressure, perceived environmental value/perceived emotional value/perceived sacrifice and intention of MSWS would be moderated by the variable of economic incentive.

In conclusion, smart waste bins can help to exert some external pressure on residents who do not obey the waste sorting rules while providing some economic reward for those who practice HSW source sorting well. Installing them can be conducive to improving residents' intention of HSW source sorting.

\section{Acknowledgements}

This study was financially supported by the National Social Science Fund of China (NSSF) (No. 19AGL017). Li-ping Zhang conceived the study and wrote the paper, while Zu-ping Zhu revised the manuscript and supervised the overall research project.

\section{Conflict of Interest}

The authors declare no conflict of interest.

\section{References}

1. ZHANG S., ZHANG M., YU X., REN H. What keeps Chinese from recycling: Accessibility of recycling facilities and the behavior. Resour. Conserv. Recycl. 109, 176, 2016.

2. World Bank: Global Waste on Pace to Triple by 2100 . Available online: http://www.worldbank.org/en/news/ feature/2013/10/30/global-waste-on-pace-to-triple. (accessed on 21/10/2019).

3. MIAN M.M., ZENG X., NASRY A.N.B., AL-HAMADANI S.M. Municipal solid waste management in China: a comparative analysis. J. Mater. Cycles. Waste. 19 (3), 1127, 2017.

4. ZHAO Y., XING W., LU W., ZHANG X., CHRISTENSEN T.H. Environmental impact assessment of the incineration 
of municipal solid waste with auxiliary coal in China. Waste. Manage. 32, 1989, 2012

5. ZHANG D., KEAT T.S., GERSBERG R.M. A comparison of municipal solid waste management in Berlin and Singapore. Waste. Manage. 30, 921, 2010.

6. GU B., WANG H., CHEN Z., JIANG S., ZHU W., LIU M., YANG J. Characterization, quantification and management of household solid waste: a case study in China. Resour. Conserv. Recycl. 98, 67, 2015.

7. TIAN H., GAO J., HAO J., LU L., ZHU C., QIU P. Atmospheric pollution problems and control proposals associated with solid waste management in China: a review. J. Hazard. Mater. 252, 142, 2013

8. PAKPOUR A.H., ZEIDI I.M., EMAMJOMEH M.M., ASEFZADEH S., PEARSON H. Household waste behaviours among a community sample in Iran: an application of the theory of planned behaviour. Waste. Manag. 34, 980, 2014.

9. ZENG C., NIU D., ZHAO Y. A comprehensive overview of rural solid waste management in China. Front. Env. Sci. Eng. 9(6), 949, 2015

10. TAI J., ZHANG W., CHE Y., FENG D. Municipal solid waste source-separated collection in China: a comparative analysis. Waste. Manag. 31 (8), 1673, 2011.

11. HAN H, ZHANG Z. The impact of the policy of municipal solid waste source-separated collection on waste reduction: a case study of China. J. Mater. Cycle. Waste. 19 (1), 382, 2017

12. MA J., HIPEL K.W., HANSON M.L., CAI X., LIU Y. An analysis of influencing factors on municipal solid waste source-separated collection behavior in Guilin, China by Using the Theory of Planned Behavior. Sustain. Cities. Soc. 37, 336, 2018.

13. VERGARA S.E., TCHOBANOGLOUS G. Municipal solid waste and the environment: a global perspective. Ann. Rev. Environ. Resour. 37, 277, 2012.

14. WAN C., SHEN G.Q., YU A. The role of perceived effectiveness of policy measures in predicting recycling behavior in Hong Kong. Resour. Conserv. Recycl. 83, 141, 2014.

15. WANG Z., YIN J., DONG X. Antecedents of urban residents' separate collection intentions for household solid waste and their willingness to pay: evidence from China. J. Clean. Prod. 173, 256, 2018.

16. FAN B., YANG W., SHEN X. A comparison study of 'motivation-intention-behavior' model on household solid waste sorting in China and Singapore. J. Clean. Prod. 211, 442, 2019.

17. NIXON H., SAPHORES J.D.M. Information and the decision to recycle: results from a survey of US households. J. Environ. Plann. Manage. 52 (2), 257, 2009.

18. GELLYNCK X., JACOBSEN R., VERHELST P. Identifying the key factors in increasing recycling and reducing residual household waste: a case study of the Flemish region of Belgium. J. Environ. Manag. 92 (10), 2683, 2011.

19. DO VALLE P.O., REIS E., MENEZES J., REBELO E. Behavioral determinants of household recycling participation: the Portuguese case. Environ. Behav. 36, $505,2004$.

20. AJZEN I., MADDEN T.J. Prediction of goal-directed behavior: Attitudes, intentions, and perceived behavioral control. J. Exp. Soc. Psychol. 22 (5), 453, 1986.

21. HOWENSTINE E. Market segmentation for recycling. Environ. Behav. 25 (1), 86, 1993.
22. ZHANG W., CHE Y., YANG K., REN X., TAI J. Public opinion about the source separation of municipal solid waste in Shanghai, China. Waste Manag. Res. 30, 1261, 2012.

23. CECERE G., MANCINELLI S., MAZZANTI M. Waste prevention and social preferences: the role of intrinsic and extrinsic motivations. Ecol. Econ. 107, 163, 2014

24. SALIMANDO J. Camden County sets the recycling page. Waste. Age. 18 (7), 48, 1987.

25. ARI E., YILMAZ V. A proposed structural model for housewives' recycling behavior: A case study from Turkey. Ecol. Econ. 129, 132, 2016.

26. KIRAKOZIAN A. One without the other? Behavioral and incentive policies for household waste management. J. Econ. Surv. 30 (3), 526, 2016

27. DEVALL W.B. Conservation: an upper-middle class social movement: a replication. J. Leis. Res. 2 (2), 123, 1970.

28. GAMBA R.J., OSKAMP S. Factors influencing community residents' participation in commingled curbside recycling programs. Environ. Behav. 26 (5), 587, 1994.

29. FENG W., REISNER A. Factors influencing private and public environmental protection behaviors: results from a survey of residents in Shaanxi, China. J. Environ. Manag. 92, 429, 2011.

30. RHODES R.E. Will the new theories (and theoreticians!) please stand up? A commentary on Sniehotta, Presseau and Araújo-Soares. Health Psychology Review. 9 (2),156, 2015.

31. ZEITHAML V.A. Consumer perceptions of price, quality, and value: a means-end model and synthesis of evidence. J. Mark. 52 (3), 2, 1988.

32. BOLTON R.N., LEMON K.N. A dynamic model of customers' usage of services: Usage as an antecedent and consequence of satisfaction. J. Mark. Res. 36 (2), 171, 1999.

33. MALONEY M.P., WARD M.P., BRAUCHT G.N. A revised scale for the measurement of ecological attitudes and knowledge. Am. Psychol. 30 (7), 787, 1975.

34. BLAHOVÁ A. L.The relevance and role of environmental values in ethics education (in the context of environmental ethics). Ethics. Bioeth. 41, 2015

35. SUKI N.M. Consumer environmental concern and green product purchase in Malaysia: structural effects of consumption values. J. Clean. Prod. 132, 204, 2016,

36. LEE J.S., LEE C.K., CHOI Y. Examining the role of emotional and functional values in festival evaluation. J. Travel. Res. 50 (6), 685, 2011.

37. FREDRICKSON B.L., BRANIGAN C. Positive emotions broaden the scope of attention and thought-action repertoires. Cogn. Emot. 19, 313, 2005.

38. MAYHEW B.W., SCHATZBERG J.W., SEVCIK G.R. The effect of accounting uncertainty and auditor reputation on auditor objectivity. Auditing: J. Pract. Theory. 20, 49, 2001.

39. LISHA C., GOH C.F., YIFAN S., RASLI A. Integrating guanxi into technology acceptance: An empirical investigation of WeChat. Telem. Inform. 34 (7), 1125, 2017.

40. THALER R. Mental accounting and consumer choice. Mark. Sci. 4 (3), 199, 1985.

41. LINZNER R., SALHOFER S. Municipal solid waste recycling and the significance of informal sector in urban China. Waste Manag. Res. 32, 896, 2014.

42. THØGERSEN J. How may consumer policy empower consumers for sustainable lifestyles? J. Consum. Policy. $\mathbf{2 8}$ (2), 143, 2005 
43. CHAMIZO-GONZALEZ J., CANO-MONTERO E.I., MUÑOZ-COLOMINA CI. Municipal Solid Waste Management services and its funding in Spain. Resour. Conserv. Recy. 107, 65, 2016.

44. ALHASSAN H., ASANTE F.A., OTENG-ABABIO M., BAWAKYILLENUO S. Application of theory of planned behaviour to households' source separation behaviour in Ghana. Manage. Environ Qual. 29 (4), 704, 2018.

45. YU Z., GUO X., ZENG Y., KOGA M., VEJRE H. Variations in land surface temperature and cooling efficiency of green space in rapid urbanization: The case of Fuzhou city, China. Urban. For. Urban Gree. 29, 113, 2018.

46. COHEN P., WEST S.G., AIKEN L.S. Applied multiple regression/correlation analysis for the behavioral sciences. Psychology Press: East Sussex, UK, 2014.

47. TAKEUCHI R., SHAY J.P., JIATAO L. When does decision autonomy increase expatriate managers' adjustment? An empirical test. Acad. Manag. J. 51 (1), 45, 2008.

48. MASON C.H., PERREAULT J.W.D. Collinearity, power, and interpretation of multiple regression analysis. J. Mark. Res. 8 (3), 268, 1991.

49. HAIR J.J.F., ANDERSON R.E., TATHAM R.L., BLACK W.C. Multivariate data analysis $\left(5^{\text {th }}\right.$ ed.); Prentice Hall: New York, USA, 1998.

50. HULIN C., NETEMEYER R., CUDECK R. Can a reliability coeffcient be too high? Consum. Psychol. 10 (1), 55, 2001.

51. BAGOZZI R.P., YI Y. On the evaluation of structural equation models. J. Acad. Mark. Sci. 16 (1), 74, 1988.

52. HAIR J.J.F., HULT G.T.M., RINGLE C. A primer on partial least squares structural equation modeling (PLSSEM); Sage publications: California, USA, 2016.

53. HAYES A.F. PROCESS: A versatile computational tool for observed variable mediation, moderation, and conditional process modeling. White paper. 2012.

54. DIGIACOMO A., WU D.W.L., LENKIC P., FRASER B., ZHAO J., KINGSTONE A. Convenience improves composting and recycling rates in high-density residential buildings. J. Environ. Plann. Manage. 61 (2), 309, 2018.

55. SINGER J., KIEU K.T., PRAVITASARI A.E. Solid Waste Management in Tourist Destinations in Developing Nations: Case Studies in Hoi An, Vietnam, and Puncak, Indonesia. Environmental Sustainability and Education for Waste Management. Springer: Singapore, 189, 2019.

56. TONGLET M., PHILLIPS P.S., READ A.D. Using the Theory of Planned Behaviour to investigate the determinants of recycling behaviour: a case study from
Brixworth, UK. Resour. Conserv. Recycl. 41 (3), 191, 2004.

57. NOMURA H., TAKAHASHI Y., YABE M. Psychological driving forces behind households' behaviors toward municipal organic waste separation at source in Vietnam: a structural equation modeling approach. J. Mater. Cycles. Waste Manage. 19 (3), 1052, 2017.

58. DIGIACOMO A., WU D.W.L., LENKIC P., FRASER B., ZHAO J., KINGSTONE A. Convenience improves composting and recycling rates in high-density residential buildings. J. Environ. Plann. Manage. 61 (2), 309, 2018.

59. ZHANG D., HUANG G., YIN X., GONG Q. Residents' waste separation behaviors at the source: Using SEM with the theory of planned behavior in Guangzhou, China. Int. J. Env. Res. Pub He. 12 (8), 9475, 2015.

60. CZAJKOWSKI M., HANLEY N., NYBORG K. Social norms, morals and self-interest as determinants of proenvironment behaviours: the case of household recycling. Environ. Resour. Econo. 66 (4), 647, 2017.

61. ABRAHAMSE W., STEG L. Social influence approaches to encourage resource conservation: a meta-analysis. Glob. Environ. Change. 23, 1773, 2013.

62. BERTOLDO R., CASTRO P. The outer influence inside us: exploring the relation between social and personal norms. Resour. Conserv. Recycl. 112, 45, 2016.

63. OSBALDISTON R., SCHOTT J.P. Environmental sustainability and behavioral science: meta-analysis of pro-environmental behavior experiments. Environ. Behav. 44, 257, 2012.

64. WANG, J., TAM Z.D., LI W.Y. Critical factors in effective construction waste minimization at the design stage: a Shenzhen case study. China. Resourc. Conserv. Recycl. 82, 1, 2014.

65. XU L., LING M., WU Y. Economic incentive and social influence to overcome household waste separation dilemma: A field intervention study. Waste. Manage. 77, $522,2018$.

66. MACIAS A., PINIARSKI W. Municipal Solid Waste Management Problems on a Local Scale: A Case Study from Rural Poland. Pol. J. Environ. Stud. 25 (4), 2016.

67. MARSHALL R.E., FARAHBAKHSH K. System approaches to integrated solid waste management in developing countries. Waste. Manage. 33, 9883, 2013.

68. WANG Y., CHENG K., WU W., TIAN H., YI P., ZHI G., LIU S. Atmospheric emissions of typical toxic heavy metals from open burning of municipal solid waste in China. Atmos. Environ. 152, 6, 2017. 